\title{
QU ${ }^{\circ}$ MICA
}

ELABORAÇÃO DE JOGOS DIDÁTICOS NO ENSINO E APRENDIZAGEM DE QUÍMICA: COM O LÚDICO TAMBÉM SE APRENDE

MORAIS. A. M.N (IFRN) NORONHA.D.V.N(IFRN) OLIVEIRA.J.B.G(IFRN) SOUSA.K.L.S(IFRN)*

FERNANDES.A.N.O(IFRN)

\section{RESUMO}

Este trabalho é fruto de uma atividade solicitada na disciplina de Epistemologia da Ciência ministrada pela professora Aleksandra Nogueira na licenciatura em Química no Instituto Federal de Educação, Ciência e Tecnologia do Rio Grande do Norte (IFRN), campus Apodi. Reflete sobre a importância dos jogos didáticos no aprendizado de Química. Trazendo possíveis soluções para dinamizar as aulas e melhorar o aprendizado do aluno. 0 trabalho tem como objetivo principal mostrar que os jogos podem ser uma forma diferenciada de aprendizagem e que pode melhorar cada vez mais o rendimento do discente em sala de aula. O jogo será aplicado na Escola Estadual Professor Antônio Dantas, numa turma da $1^{\circ}$ série do Ensino Médio, no munípio de Apodi no Rio Grande do Norte. A pesquisa encontra-se em andamente, mas é perceptível que o lúdico torna o ensino mais eficaz e ajuda a fixar o que o professor explica em sala de aula.

PALAVRAS-CHAVE: Jogo didático, química, aprendizado.

\section{ELABORATION OF DIDACTIC GAMES IN THE TEACHING AND LEARNING OF CHEMISTRY: WITH THE PLAYFUL ALSO LEARN}

\section{ABSTRACT}

This work is the resulto $f$ a requested activity in the discipline of Epistemology of Science being activity in the teacher Aleksandra Nogueira on degree in chemistry at Instituto Federal de Educação, Ciência e Tecnologia do Rio Grande do Norte (IFRN), campus Apodi. Reflects on the importance of educational games for learning chemistry. Bringing possible solutions to streamline and improve student learning. The work has as its main objective show that games can be a diferente way of learning and that can improve the performance of students in the classrom. The game will be applied on Estadual Professor Antônio Dantas, a classe of $1^{\circ}$ high school series, in Apodi município is in progress, but it is noticeable that the playful makes teaching more effective and helps to establish what the teacher explains in the classroom.

KEY-WORDS: Educational game, chemistry, learning. 


\section{ELABORAÇÃO DE JOGOS DIDÁTICOS NO ENSINO E APRENDIZAGEM DE QUÍMICA: COM O LÚDICO TAMBÉM SE APRENDE}

\section{INTRODUÇÃO}

Percebemos que um dos grandes desafios dos professores de química atualmente é a falta de interação com os alunos (as). Para que essa realidade seja mudada os professores tem que aplicar aulas diferenciadas.

Segundo Miranda (2001) os jogos didáticos podem atingir vários objetivos, relacionados à cognição, afeição, socialização, motivação e criatividade. Sendo assim, a aplicação de jogos em sala de aula é muito importante e merece a atenção de todos os professores de química, principalmente os que estão em processo de formação, pois há uma grande necessidade de reformulações no ensino de química.

Nesse sentido, é perceptível que parte dos professores repassa o seu conhecimento através de aulas expositivas, em que fazem pouco uso de recursos lúdicos na aula, nessas condições acontece o fracasso e o desinteresse dos alunos pela disciplina. É nesse contexto que os jogos didáticos destacam-se como um instrumento de motivação para o aprendizado em química e estimula o interesse do aluno.

Na química, as primeiras referências propostas sobre jogos no ensino foi no artigo publicado na Revista Química Nova, no ano de 1993 (CRAVEIRO et al, 1997), com o jogo: Química: um palpite inteligente, o que é um tabuleiro compostos por perguntas e respostas. Em 1997, Beltran traz na revista Química Nova na Escola, uma simulação para o comportamento de partículas, utilizado modelos para fusão, recristalização ou dissolução de substancias.

Já no ano de 2000, Eichlere Del Pino publicaram na revista Química Nova na Escola, um artigo apresentado o software Carbópolis que simula situações ambientais por meio de questões-problema. No mesmo ano Cunha propõe um livro/manual, que foi apresentado durante um minicurso no X Encontro Nacional de Ensino em Química (Porto Alegre, RS), cuja finalidade era apresentar propostas de jogos a acadêmicos, pesquisadores e professores.

Em 2003 Soares, Okumura e Cavalheiro apresentaram uma proposta de jogo para trabalhar o conceito de equilíbrio químico, nesta publicação foi proposto a montagem de uma simulação com bolas de isopor dispostas em caixas que trocam elementos entre si, como uma analogia ao conceito de equilíbrio químico.

Enquanto que em 2004, o professor e pesquisador Marlon Soares apresentou em sua tese de doutorado na Universidade de São Carlos: Jogos e atividades lúdicas aplicados ao ensino de química, e torna-se a grande referência para o estudo de jogos no ensino de química. No ano de 2005 novamente é publicada mais uma atividade lúdica na revista Química Nova na Escola apresentado pelos autores Soares e Oliveira, este artigo tem como objetivo a simulação de um júri para a discussão de um problema ambiental. 
No ano seguinte, 2006, mais um artigo sobre jogo é publicado na revista Química Nova na Escola pelo os autores Soares e Cavalheiro, a proposta desta vez é apresentada a partir de um jogo de tabuleiro denominado ludo,o jogo é apresentado na forma de encarte, sendo possível sua confecção, tendo como objetivo discutir os conceitos da termodinâmica.

Em 2008 é publicado o livro jogos para o ensino de química: teoria, métodos e aplicações (SOARES, 2008), que tem sido uma boa referência paraaqueles que desejam pensar no lúdico para sala de aula, bem como um referencial importante para a formação de professores nos cursos de Graduação, Licenciatura ou formação continuada. Em 2009, a revista Química Nova na Escola publica dois artigos sobre jogos/lúdico.

Com a quantidade de trabalhos escritos nota-se a importância e ao mesmo tempo a preocupação que se tem em desenvolver aulas mais didáticas no ensino de química. Compreendemos que a disciplina de química apresenta muitas fórmulas, símbolos e conceitos, assim sendo, exige abstração para ser entendida pelos alunos. E o jogo didático visa estimular o aprendizado dos mesmos e tornar as aulas mais dinâmicas.

\section{METODOLOGIA}

Os jogos químicos é um incentivo para motivar o aluno, facilitando-lhe o processo de ensino aprendizagem e assim despertando seu interesse para aumentar o seu conhecimento, dessa forma, os jogos se apresentam como um recurso didático no ensino químico, visando o aprendizado enquanto utilizam o recurso. Com a finalidade de tornar as aulas química mais atrativas e facilitar o aprendizado do aluno, os jogos é uma solução mais viável para as escolas. Neste sentido, Silva (2006) afirma:

\footnotetext{
A introdução dos jogos no ambiente escolar facilita o processo na busca do aluno pelo conhecimento, despertando o seu interesse pelas novas experiências e descobertas através de situações estimuladoras. A aprendizagem proporcionada através das atividades lúdicas passa a ter uma significação mais intensa e vai acompanhar o educando durante toda sua vida, visto que o conhecimento adquirido é interiorizado e, quando necessário, expresso de maneira interativa.
}

Quase todos os jogos químicos têm como objetivo de sistematizar e revisar os conteúdos aprendidos, com os professores que lecionam dentre eles estão: tabela periódica, modelos atômicos e seus cientistas que elaboram estrutura atômica, entre outros.

A ideia da formação de jogo está sendo pensado para ser aplicado em uma turma de 1a série do Ensino Médio na Escola Estadual Professor Antônio Dantas no município de Apodi/RN, mas pode ser utilizado nos demais anos do desse nível de ensino. Para analisar os resultados dessa pesquisa, pretendemos aplicar questionário avaliativo com perguntas abertas e fechadas para os alunos que utilizarem o jogo como forma de aprendizado.

O jogo terá um formato de tabuleiro, onde terão perguntas relacionadas ao conteúdo de química da 1a série. Para o aluno passar de fase no jogo ele terá que acertar todas as perguntas, e no final ele terá uma recompensa que ficará a critério do professor que está aplicando o jogo, como forma de estímulo para o aluno. 


\section{FUNDAMENTAÇÃO TEORICA}

A utilização de jogos didáticos no ensino de química é alvo de várias pesquisas que defende o uso do mesmo como um processo de ensino-aprendizado, sobre isso Neto (1996) afirma que se o ensino for lúdico e desafiador, a aprendizagem prolonga-se fora da sala de aula, fora da escola, pelo cotidiano, num crescimento muito mais rico do que algumas informações que o aluno decora.

Segundo Melo (2005), muitos estudos a respeito de atividades lúdicas, comprovam que, o jogo além de ser fonte de descoberta e prazer para o aluno, está inserido também no contexto sócio-histórico, refletido na cultura.

A aplicação de jogos didáticos no ensino de química é uma maneira de mudar a realidade das aulas química e mudar a opinião de muitos alunos que acham a disciplina complexa e abstrata. De acordo com Santana e Wartha (2006) o jogo didático ou pedagógico é aquele fabricado com o objetivo de proporcionar determinadas aprendizagens, diferenciando-se do material pedagógico, por conter o aspecto lúdico, e utilizado para atingir determinados objetivos pedagógicos, sendo uma alternativa que pode, também, melhorar o desempenho dos estudantes em determinados conteúdos.

\section{CONSIDERAÇÕES FINAIS}

Diante do que foi apresentado é possível perceber a importância dos jogos educativos no processo educacional. É importante que o professor busque sempre diversificar suas aulas e torná-las mais interessante. Os jogos educativos é uma boa opção para uma aula diferenciada e divertida, pois ajuda no processo educacional, na sociabilidade, concentração, e principalmente no processo de aprendizagem.

Dessa forma os jogos são recursos auxiliadores importantes para serem utilizados em sala de aula, pois faz com o aluno se interessem pelos conteúdos abordados em sala de aula despertando o desejo de aprender.

\section{AGRADECIMENTOS}

Os autores agradecem ao Instituto Federal de Educação, Ciência e Tecnologia do Rio Grande do Norte - IFRN, Campus Apodi por nos proporcionar um ensino de qualidade. A Deus pelo dom da vida e a todos os colegas do 3o período da Licenciatura em Química.

\section{REFERÊNCIAS}

BELTRAN, N.O. Ideais em movimento. Revista Nova na Escola. N.5, maio 1997

BENEDETTI FILHO, E; FLORUCCI, A.R; BENEDETTI, L.S. E CRAVEIRO J.A. Palavras cruzadas como recurso didático no ensino da teoria atômica. Revista Nova na Escola, n.31, maio 2009.

CABRERA, W.B.; SALVI, R.A. LUDICIDADE NO ENSINO MÉDIO: ASPIRAÇÕES DE PESQUISA NUMA PERSPECTIVA CONSTRUTIVISTA. In: ENCONTRO NACIONAL DE PESQUISA EM EDUCAÇÃO EM CIÊNCIAS, 5. Atas, 2005.

CRAVEIRO, A.A. et.al. Química um palpite inteligente. Revista Nova na Escola. 16:3, 1993, p.234-236. 
CUNHA, M.B. Jogos didáticos de química. Santa Maria: Grafos, 2000 et.al. Jogos na Educação Química: Algumas considerações. In. ENCONTRO PAULISTA DE PESQUISA EM ENSINO DE QUÍMICA, 6, 2011. Atas... São Carlos, 2011.

EICHER, M. e DEL PINO, J.C. Carbópolis: Um software para educação química. Revista Nova Escola, n.11, maio 2000.

MELO, C.M.R. AS ATIVIDADES LÚDICAS SÃO FUNDAMENTAIS PARA SUBSIDIAR AO PROCESSO DE CONSTRUÇÃO DO CONHECIMENTO. Información Filosófica. V.2 nํ1 2005.

MIRANDA, S. NO FASCÍNIO DO JOGO, A ALEGRIA DE APRENDER. In: Ciência Hoje, v.28, p. 64-66. 2001.

NETO, Carlos Alberto Ferreira. MOTRICIDADE E JOGO NA INFÂNCIA. Rio de Janeiro: Sprint, 1996.

SANTANA, E. M., WARTHA, E. O ENSINO DE QUÍMICA ATRAVÉS DE JOGOS E ATIVIDADES LÚDICAS BASEADAS NA TEORIA MOTIVACIONAL DE MASLOW. Atas do XIII Encontro Nacional de Ensino de Química, 2006.

SANTOS, A.P.B; MICHEL, R.C. Vamos jogar suequímica?Revista Química Nova na Escola, n. 31, agosto 2009.

SILVA, I. F.O.; O PAPEL DE ATIVIDADES LÚDICAS NA PRODUÇÃO DE TEXTOS DISSERTATIVOS. Universidade Católica de Pernambuco - UNICAP - Recife 2006.

SOARES, M.H.F.B; OKUMURA, F; CAVALHEIRO, E.T.G. Proposta de um jogo didático para o ensino do conceito de equilíbrio químico. Revista Química Nova na Escola, n. 18, novembro 2003.

SOARES, M.H.F.B. Jogos para o ensino de química: teoria, métodos e aplicações. Guarapari: ExLibris, 2008a.

Jogos e atividades lúdicas no ensino de química: Teoria, métodos e aplicações. In. ENCONTRO NACIONAL DE QUÍMICA, 14, 2008. Curitiba: UFPR, 2008b.

. O lúdico em química: jogos e atividades lúdicas aplicados ao ensino de química. 2004. 195 f. Tese (doutorado)- Universidade Federal de São Carlos, São Carlos, 2004. 